\title{
Research on capacity configuration method of microgrid considering system cost
}

\author{
Ning $\mathrm{Hu}^{1, \mathrm{a},}$ Juncheng Si ${ }^{2, b,}$ Yuanyuan Wang ${ }^{3, \mathrm{c},}$ Dehua Wang ${ }^{4, \mathrm{~d},}$ Hanghang Liu ${ }^{5, \mathrm{e},}$ Guanglei $\mathrm{Li}^{6, \mathrm{f}}$ \\ ${ }^{1}$ State Grid Shandong Power Supply Company \\ State Grid Dongying Power Supply Company Dongying, China \\ ${ }^{2}$ State Grid Shandong Power Supply Company \\ State Grid Dongying Power Supply Company Dongying, China \\ ${ }^{3}$ State Grid Shandong Power Supply Company \\ State Grid Dongying Power Supply Company Dongying, China \\ ${ }^{4}$ State Grid Shandong Power Supply Company \\ State Grid Shandong Electric Power Research Institute Jinan, China \\ ${ }^{5}$ State Grid Shandong Power Supply Company \\ State Grid Dongying Power Supply Company Dongying, China \\ ${ }^{6}$ State Grid Shandong Power Supply Company \\ State Grid Shandong Electric Power Research Institute Jinan, China
}

\begin{abstract}
Microgrid is a new type of power supply structure and will play an important role in ensuring power supply. Because of the high cost of micro grid construction, this is very necessary to determine the lowest capacity configuration and realize the best function configuration, which is an urgent problem in engineering construction. Therefore, this paper first establishes simulation analysis model, puts forward economic optimization model and constraints, and formulates system configuration scheme and construction cost. The results show that the method is feasible and effective. This scheme not only reduces the operation cost of the system, but also provides a reference for the construction of microgrid engineering.
\end{abstract}

\section{INTRODUCTION}

Microgrid is an effective way to deal with the current energy and resource problems. Microgrid mainly consists of distributed generation, load, energy storage device and control device. This is a new network structure in power grid construction. Renewable energy such as wind energy and solar energy on the island is rich in resources, but its characteristics of intermittency and volatility bring great difficulties to system operation scheduling.

Due to the special geographical location of the island, the difficulty of power quality supply restricts the development of the island. At present, the main power supply for islands is to connect the onshore power grid by submarine cables, and diesel generators are arranged on the islands. But this method has many disadvantages. Submarine cables are easily damaged, the reliability of power supply is poor, and maintenance is difficult. Diesel generators generate sulfides and nitrides, which pollute the environment.

Although Diesel generator output is stable,the high cost of power generation and exhaust emissions seriously pollute the environment. Literature [1,2] used the enumeration method to obtain the photovoltaic and energy storage capacity configuration scheme that meets the reliability constraint of the power supply of the microgrid system and has the lowest cost, but the optimization efficiency is low. Literature $[3,4]$ established the microgrid grid and off-grid two operating modes under the economic model, respectively, to obtain different optimal energy storage capacity. In order to ensure the economic operation of island power grids, distributed power and submarine cables are used to provide reliable power supply to islands. Therefore, priority is given to the use of new energy sources such as scenery, with the lowest comprehensive economic cost as the objective function.

New energy generation is intermittent and fluctuating, and the load is also fluctuating. However, diesel generators are not suitable for large-scale use due to their characteristics of high noise and serious pollution. Energy storage batteries are clean and environmentally friendly and play a role in energy buffering, but they are expensive. Under the influence of various factors such as external force damage and self-aging, the output of the submarine cable is intermittent.

\footnotetext{
asddyhn19@sohu.com bdysjc@163.com cdlwyy@sohu.com disddlwdhl@126.com edylhh@126.com

flovexjtulgl@126.com
} 
Literature [5,6] put forward the multi-objective optimization design method of independent micro-grid for chaihu scenery. The linear weighted summation method was used to convert the multi-objective optimization problem to single-objective optimization problem. However, the weight factors of different targets were difficult to reasonably determine, The increase can only be indirectly constrained by increasing the power penalty coefficient. In the process of system construction, it is necessary to consider the economic investment restrictions, technical reliability restrictions and other factors. It is necessary to optimize the capacity allocation of energy storage system, and finally determine a reasonable construction scale. Aiming at the optimal allocation of distributed power capacity proposed in engineering construction, this paper considered various constraints and analyze the influence of system parameters on the optimization results.

\section{DISTRIBUTED POWER MATHEMATICAL MODEL}

\subsection{Wind turbine}

The approximate relationship between wind turbine output power and wind speed can be expressed by the following function [7.8].

$$
P_{\mathrm{W}}(v)= \begin{cases}0 & 0 \leqslant v \leqslant v_{\text {in }} \\ P_{\mathrm{WT}} \frac{v-v_{\text {in }}}{v_{\mathrm{r}}-v_{\text {in }}} & v_{\text {in }}<v \leqslant v_{\mathrm{r}} \\ P_{\mathrm{WT}} & v_{\mathrm{r}}<v \leqslant v_{\text {out }} \\ 0 & v_{\text {out }}<v\end{cases}
$$

In the formula, $P_{\mathrm{WT}}$ is the fan rated power. $v_{\text {in }}$ in is the cut in wind speed. $v_{r}$ is the rated wind speed. $v_{\text {out }}$ is the cut out wind speed. According to the manufacturer's data, the rated power is $750 \mathrm{~kW}$, the cutting speed is 3.5 $4.0 \mathrm{~m} / \mathrm{s}$, the rated speed is $14 \mathrm{~m} / \mathrm{s}$ and the cutting speed is $25 \mathrm{~m} / \mathrm{s}$.

\subsection{Photovoltaic power supply}

In order to facilitate the engineering application, it is considered that the output of photovoltaic power supply is only related to light intensity and ambient temperature .

$$
P_{\mathrm{V}}=P_{\mathrm{STC}} G_{\mathrm{C}} \frac{1+k\left(T_{\mathrm{C}}-T_{\mathrm{STC}}\right)}{G_{\mathrm{STC}}}
$$

In the above formula, $P_{\mathrm{v}}$ is the output power of photovoltaic power supply, $P_{\mathrm{STC}}$ is the rated power of photovoltaic power supply. $G_{\mathrm{C}}$ is the radiation intensity of working point, $T_{\mathrm{C}}$ is the surface temperature of the battery, its value is similar to the ambient temperature, the rated temperature is $25{ }^{\circ} \mathrm{C} . k$ is the power temperature coefficient. In this paper, the model YI5C-200M photovoltaic cells, the rated output power of $200 \mathrm{~W}$, the design life of 15 years.

Battery life is usually defined when the actual capacity is $80 \%$ of the rated capacity which corresponds to the cycle life or calendar life. The decrease in capacity is mainly due to the decrease in solution concentration and the increase in battery internal resistance, which are related to charge and discharge power and operating temperature.

The remaining value of a lithium-ion battery can be determined by the state of health. When the capacity decreases by $80 \%$ from the rated capacity. The capacity decay rate is related to the average SOC and SOC deviation.

According to the principle of conservation of energy, the charging and discharging of the storage battery system at any given time can satisfy operation requirements. When the battery is charging, the result is calculated as follows.

$$
E_{\text {bat }}(t)=E_{\text {bat }}(t-1)(1-\delta)+P_{\text {bat_c }}(t) \eta_{\mathrm{c}}
$$

In the above formula, $E_{\text {bat }}(t), E_{\text {bat }}(t-1)$ are the remaining battery capacity $(\mathrm{kWh})$ at the end of the current stage and previous stage respectively. $\delta$ represents the quota of the system. $P_{\text {bat_c }}(t)$ is the charging power $(\mathrm{kW})$ of the battery system to the external grid in the period. $\eta_{\mathrm{c}}$ is the charging efficiency (\%) of the battery system.

When the battery is discharged, it can be expressed as follows.

$$
E_{\text {bat }}(t)=E_{\text {bat }}(t-1)(1-\delta)-\frac{P_{\text {bat_d }}(t)}{\eta_{\mathrm{d}}}
$$

In the above formula, $P_{\text {bat_d }}(t)$ is the discharging power $(\mathrm{kW})$ of the battery system to the external grid in the current stage. $\eta_{\mathrm{d}}$ is the discharging efficiency of the battery system.

\section{ECONOMIC OPTIMIZATION MODEL}

\subsection{The objective function}

The optimization object of this paper is the total cost of microgrid investment operation converted to one year, which is composed of three parts such as the initial investment cost of equipment, the replacement cost of equipment replacement and the maintenance cost of microgrid[9].

In summary, the establishment of micro-economic goal function.can be expressed as follows..

$$
\min C=C_{\mathrm{I}} \mathrm{CRF}(r, L)+C_{\mathrm{R}}+C_{\mathrm{Y}}
$$


In the above formula, $C_{\mathrm{I}}$ is the initial investment cost of the equipment. $C_{\mathrm{R}}$ is the replacement cost of the equipment. $C_{\mathrm{Y}}$ is the maintenance and operation cost of the micro grid. $r$ is the actual loan interest rate. $L$ is the engineering cycle, this article takes 25 years. $\operatorname{CRF}(r, L)$ is the annual fund recovery rate, which is calculated as follows.

$$
\begin{aligned}
\operatorname{CRF}(r, L) & =\frac{r(1+r)^{L}}{(1+r)^{L}-1} \\
r & =\frac{i-f}{1+f}
\end{aligned}
$$

In the above formula, $i$ is the nominal lending rate (now $6.55 \%$ ) over 5 years and $\mathrm{f}$ is the inflation rate (now $3 \%)$.

\subsection{Equipment initial investment costs}

Equipment initial investment costsis can be calculated as follows.

$$
C_{\mathrm{I}}=N_{\mathrm{WT}} C_{\mathrm{WT}}+N_{\mathrm{PV}} C_{\mathrm{PV}}+N_{\mathrm{bat}} C_{\mathrm{bat}}+N_{\mathrm{EN}} C_{\mathrm{EN}}
$$

In the above formula, $N_{\mathrm{WT}}$ represents the number of wind turbines, $C_{\mathrm{WT}}$ represents the purchase price of wind turbine. $\quad N_{\mathrm{PV}}$ represents the number of photovoltaic power generation, $C_{\mathrm{PV}}$ represents the purchase price of photovoltaic power generation. $N_{\text {bat }}$ represents the number of energy storage battery, $C_{\text {bat }}$ represents the purchase price of energy storage battery. $N_{\mathrm{EN}}$ represents the number of diesel generator, $C_{\mathrm{EN}}$ represents the purchase price of diesel generator.

\subsection{Equipment replacement costs}

Equipment replacement costs can be calculated as follows

$$
C_{\mathrm{R}}=C_{\mathrm{RB}}+C_{\mathrm{RW}}+C_{\mathrm{RPV}}+C_{\mathrm{REN}}
$$

In the above formula, $C_{\mathrm{RB}}, C_{\mathrm{RW}}, C_{\mathrm{RPV}}, C_{\mathrm{REN}}$ respectively represent the annual replacement cost of energy storage battery, wind turbines, photovoltaic power generation and diesel generator.

\subsection{Constraints}

Consider the actual footprint of the distributed power supply and load spikes that constrain the maximum number of fans, PV cells, storage batteries, and diesel generators.

$$
\left\{\begin{array}{l}
N_{\mathrm{WT}} \leqslant N_{\mathrm{WT}, \max } \\
N_{\mathrm{PV}} \leqslant N_{\mathrm{PV}, \text { max }} \\
N_{\mathrm{bat}} \leqslant N_{\text {bat,max }} \\
N_{\mathrm{EN}} \leqslant N_{\mathrm{EN}, \text { max }}
\end{array}\right.
$$

In the above formula, $N_{\mathrm{WT} \text {,max }}, N_{\mathrm{PV} \text {,max }}, N_{\text {bat,max }}$, $N_{\text {EN,max }}$ respectively represent the maximum number of wind turbines, photovoltaic power generation, energy storage battery and diesel generator..

\section{EXAMPLE ANALYSIS}

Compared with the two schemes of the latter cost of initial investment of blower, photovoltaic and storage battery is increased, the investment and running cost of diesel generator is reduced, resulting in the decrease of total cost, and the cost of diesel generator The proportion of power supply (the ratio of annual generating capacity of diesel generators to the total annual electricity consumption of the load) is reduced from $45.17 \%$ to $36.28 \%$. Table 1 shows several types of distributed power cost data.This indicate that the energy storage access helps to increase the proportion and mitigation of renewable energy supply Environmental pollution.

By comparing the total cost of investment and operation of microgrids in five configurations, it is found that the cost of storing wood for scenery is the best, followed by the scenery wood, and finally the wind wood, the light wood and the light storage. The best wind, light, storage, firewood are four kinds of power are configured, so that one way can achieve the complementary scenery, on the other hand through energy storage to meet some of the peak load power demand, reduce diesel generator output, and thus reduce the operating costs of micro-grid.

TABLE I. CALCULATION RESUlts

\begin{tabular}{|c|c|c|c|c|c|}
\hline Power types & $\begin{array}{c}\text { Buy cost } \\
\text { (Million/ } \\
\text { Taiwan) }\end{array}$ & $\begin{array}{c}\text { Replace } \\
\text { cost } \\
\text { (Million/ } \\
\text { Taiwan) }\end{array}$ & $\begin{array}{c}\text { Maintenance } \\
\text { costs } \\
\text { [Yuan / } \\
\text { (Taiwan } \\
\text { year)] }\end{array}$ & $\begin{array}{c}\text { fuel } \\
\text { cost/ } \\
\text { (Yuan } \\
\text { /L) }\end{array}$ & $\begin{array}{c}\text { Pollution } \\
\text { penalties / } \\
\text { [Yuan / } \\
\text { (kW h)] }\end{array}$ \\
\hline $\begin{array}{c}\text { Wind } \\
\text { turbines }\end{array}$ & 400 & 380 & 8000 & 0 & 0 \\
\hline $\begin{array}{c}\text { Photovoltaic } \\
\text { power } \\
\text { generation }\end{array}$ & 0.22 & 0.2 & 5 & 0 & 0 \\
\hline $\begin{array}{c}\text { Energy } \\
\text { storage } \\
\text { battery }\end{array}$ & 1.2 & 1 & 240 & 0 & 0 \\
\hline $\begin{array}{c}\text { Diesel } \\
\text { generators }\end{array}$ & 40 & 35 & 16000 & 8 & 0.008 \\
\hline
\end{tabular}

This article takes the long-running island microgrid as the research object, uses distributed power and submarine cables to supply power to the island, and preferentially uses new energy such as wind and sunlight. The objective is to use the lowest comprehensive economic cost as the objective function. Constraints model is established, and the advanced algorithm is used to solve the problem. Compared with the upgraded submarine cables, the rationality and economics of the island microgrid running on the grid are analyzed. With power supply reliability and power balance as constraints, an optimal capacity allocation model was established, which was solved using advanced algorithms, compared with upgrading submarine cables, and analyzing the rationality and economics of island microgrids that were connected to the grid. 


\section{CONCLUSION}

Considering the high cost of micro grid construction, this paper analyzes the operation characteristics of micro grid and establishes a simulation analysis model. From the aspects of initial construction cost, annual operation cost and constraints, the calculation method of micro grid cost is established. Finally, the system configuration scheme and construction cost are worked out. This scheme is conducive to the capacity optimization of microgrid, and can provide a reference for the planning and design of microgrid.

\section{ACKNOWLEDGMENT}

This work was supported by Science and technology project of State Grid Shandong Power Supply Company.

\section{REFERENCES}

1. Zhang Jiajia, Chen Jinfei et al, “ Investigation of the influence of microgrids high large penetration ratios on power network stability," Journal of Electric Power Science and Technology, vol. 24, pp. 25-30, April 2009.

2. Yu Peng, Liu Xinghua et al, "Study on operation control of island microgrid with high renewable energy penetration," Power System Technology, vol. 42, pp. 779-788, August 2018.

3. Wan Chengshan, Wu Zhen et al, " Research on key technologies of microgrid," Transactions of China Electrotechnical Society, vol. 29, pp. 1-9, August 2014.
4. Wang Zhaoyu, Ai Qian et al, " Multi-objective allocation of microgrid in smart distribution network," Power System Technology, vol. 36, pp. 200-203, June 2012.

5. Ye Chengjin, Huang Minxiang et al, "Optimization of wind and solar power system based on discrete probability model," Automation of Electric Power Systems, vol. 37, pp. 48-54, March 2013.

6. Ma Rui, Jin Yan et al, “ An Optimal Dual-layer Configuration of Active Distribution Network Based on Chance-constrained Programming," Transactions of China Electrotechnical Society, vol. 31, pp. 145-154, June 2016.

7. Liu Ziqiu, Huang Mingxiang et al, “ Optimal energy allocation of microgrid based on reliability and economy by considering characteristics of micro source," Power System Technology, vol. 38, pp. 1352-1357, June 2014.

8. Dai Juchuan, Liu Deshun et al, " Research on power coefficient of wind turbines based on SCADA data," Renewable Energy, vol 86, pp. 206-215, October 2016.

9. Lin Shaobo, Han Minxiao et al, “ A capacity allocation method for distributed PV distribution network based on stochastic prediction error," Proceedings of the CSEE, vol. 33, pp. 25-32, June 2013.

10. Dai Juchuan, Liu Deshun et al, " Research on power coefficient of wind turbines based on SCADA data," Renewable Energy, vol. 86, pp. 206-215, June 2016.

11. Yuan Hongliang, Hu Yi et al, "Operation-data-based Assessment of reliability of WTG Power Curve," Northwest Hydropower, vol. 5, pp. 80-83, June 2018.

12. Zaher $\mathrm{A}, \mathrm{Mcarthur} \mathrm{S}$ et al, "Online wind turbine fault detection through automated scada data analysis," Wind Energy, vol. 12, pp. 574-593, October 2019.

13. Kusiak A, Li Wenyan et al, " The prediction and diagnosis of wind turbine faults," Renewable Energy, vol. 36, pp. 16-23, October 2011. 